\title{
Three-dimensional numerical analysis to predict behavior of driftage carried by tsunami
}

\author{
Nozomu Yoneyama ${ }^{1}$, Hiroshi Nagashima ${ }^{2}$, and Keiichi Toda ${ }^{1}$ \\ ${ }^{1}$ Disaster Prevention Research Institute, Kyoto University, Gokasho, Uji, Kyoto 6110011, Japan \\ ${ }^{2}$ Newjec Inc., 2-3-20 Honjohigashi, Kita, Osaka 5310074, Japan
}

(Received December 7, 2010; Revised November 5, 2011; Accepted November 30, 2011; Online published October 24, 2012)

\begin{abstract}
This study aims to develop a three-dimensional (3D) numerical analysis code for the prediction of driftage behavior during a tsunami. The main features of this code are as follows: (1) it can simulate the six degree-offreedom motion of driftage in a 3D flow field; (2) it can consider the interaction between fluid flow and driftage motion; and (3) it can compute the impact of the collision with a wall based on the Lagrangian equation of impulsive motion. In this code, we assume that the fluid pressure and viscosity cause driftage motion and that driftage motion affects fluid flow through deformation of the boundary between the fluid and itself. The code was applied to a hydraulic experiment carried out by subjecting a wooden body to an abrupt flow of water. The obtained numerical solution of driftage motion agreed well with the experimental result. It is concluded that our code can be used to successfully predict the behavior of driftage carried by a tsunami.
\end{abstract}

Key words: Three-dimensional numerical analysis, tsunami, driftage, six degree-of-freedom motion.

\section{Introduction}

During the Indian Ocean Tsunami in 2004, rubble, cars, etc., drifted toward coastal areas with the receding waves and destroyed buildings and structures. Rubble from destroyed structures was also adrift, causing increased damage. To reduce such damage, it is essential to predict the behavior and collision force of tsunami driftage. Ushijima et al. (2006) and Kawasaki et al. (2006) proposed methods for the three-dimensional (3D) simulation of tsunami driftage. These methods can simulate driftage behavior accurately by treating the driftage as a fluid; however, they also have to simulate the air flow. In this study, we have developed a numerical method that does not require the simulation of the air flow to predict the driftage behavior across a wide coastal area. Yoneyama et al. (2002) performed a numerical analysis of the locally high run-up caused by the 1993 Hokkaido-Nansei-Oki seismic tsunami. The wave height calculated by them agreed well with the actual wave height. We believe that the driftage behavior can be simulated with a high degree of accuracy by appending a driftage simulation function to their fluid analysis code. We had developed a vertical two-dimensional (2D) analysis code based on this method, and had verified its validity (Nagashima et $a l ., 2008)$. In this study, we developed a new 3D numerical analysis code that can simulate the six degree-of-freedom motion of driftage. We verified the validity of this code by comparing the obtained results with a numerical result and with the results of hydraulics model test.

Copyright (c) The Society of Geomagnetism and Earth, Planetary and Space Sciences (SGEPSS); The Seismological Society of Japan; The Volcanological Society of Japan; The Geodetic Society of Japan; The Japanese Society for Planetary Sciences; TERRAPUB.

doi:10.5047/eps.2011.11.010

\section{Numerical Analysis Method}

Our method treats the driftage as a rigid body that is set in motion by the gravitational and fluid forces; these forces are determined by a fluid analysis (see Fig. 1). Meanwhile, the fluid analysis treats the driftage as a moving boundary that is expressed in terms of the porosity ratio of the computational cell $\gamma^{\mathrm{v}}$ and the aperture ratio of the cell surface $\gamma^{\mathrm{a}}$ (see Fig. 2).

The movement of driftage causes a change in the porosity ratio and in the aperture ratio of the computational cell. This change affects the fluid flow; this effect can be expressed by the following continuity equation.

\subsection{Basic equations for fluid flow}

The basic equations of fluid flow are shown below. - Continuity equation

$$
\frac{\partial \gamma^{\mathrm{v}}}{\partial t}+\frac{\partial \gamma_{j}^{\mathrm{a}} \bar{u}_{j}}{\partial x_{j}}=0
$$

- Motion equation $(i=1,2,3)$

$$
\frac{\partial \bar{u}_{i}}{\partial t}+\frac{\gamma_{j}^{\mathrm{a}} \bar{u}_{j}}{\gamma^{\mathrm{v}}} \frac{\partial \bar{u}_{i}}{\partial x_{j}}=g_{i}-\frac{1}{\rho} \frac{\partial \bar{p}}{\partial x_{i}}+\frac{\partial}{\partial x_{j}}\left(\nu \frac{\partial \bar{u}_{i}}{\partial x_{j}}-\overline{u_{i}^{\prime} u_{j}^{\prime}}\right)
$$

- Advection equation of fluid

$$
\frac{\partial \gamma^{\mathrm{v}} F}{\partial t}+\frac{\partial \gamma_{j}^{\mathrm{a}} F \bar{u}_{j}}{\partial x_{j}}=0
$$

where $u_{i}$ is the component of flow velocity; $g_{i}$, the component of the external force per unit volume (vector representation is $g$ ); $p$, the pressure; $\rho$, the density of the fluid; $v$, the dynamic viscosity; $F$, the fluid-filling ratio of the void in a cell; ${ }^{-}$, the Reynolds averaging quantity; and ', the fluctuation in the Reynolds averaging quantity. We also used the 


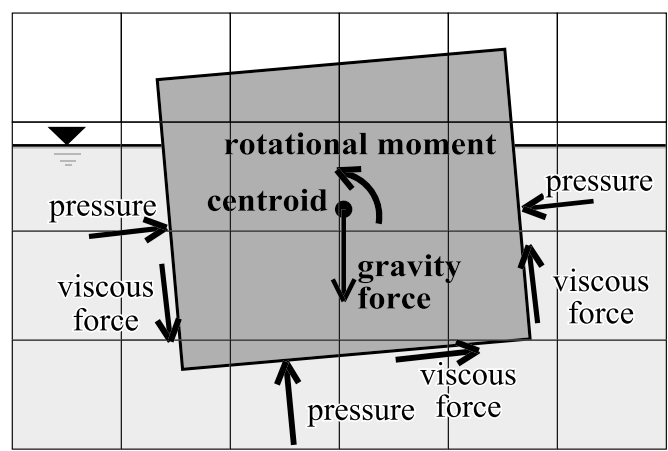

Fig. 1. Drift motion.

\begin{tabular}{|c|c|c|c|c|c|}
\hline$A$ & $A$ & $A$ & $A$ & $A$ & $A$ \\
\hline$A$ & $\begin{array}{l}{ }^{v}{ }^{\mathrm{A}}={ }^{\mathrm{A}} \\
F=0.8 \\
F=0.0\end{array}$ & $\begin{aligned} & A \\
\gamma^{v} & =0.5 \\
F & =0.0\end{aligned}$ & $\begin{array}{c}\stackrel{A}{\gamma^{v}=0.4} \\
F=0.0\end{array}$ & $\begin{array}{c}\gamma^{v} \stackrel{A}{=}=0.6 \\
F=0.0\end{array}$ & $A$ \\
\hline $\bar{F}$ & $\begin{array}{c}\gamma^{v}=0.5 \\
F=0.6\end{array}$ & $\begin{array}{rl}0 & 0 \\
\gamma^{v}=0.0 \\
F=0.0\end{array}$ & $\begin{array}{l}\gamma^{v}=0.0 \\
F=0.0\end{array}$ & $\begin{array}{c}S \\
\gamma^{v}=\overline{0.4} \\
F=0.6\end{array}$ & $S$ \\
\hline$F$ & $\begin{array}{c}\boldsymbol{F} \\
\gamma^{v}=0.7 \\
F=1.0\end{array}$ & $\begin{array}{c}\mathrm{F} \\
\gamma^{v}=0.1 \\
F=1.0\end{array}$ & $\begin{array}{c}\mathrm{F} \\
\gamma^{v}=0.2 \\
F=1.1 . \theta\end{array}$ & $\begin{array}{c}F \\
\gamma^{v}=0.5 \\
-F=1.0\end{array}$ & $F$ \\
\hline$F$ & $F$ & $F$ & $F$ & $F$ & $F$ \\
\hline
\end{tabular}

A: (Air cell), S: (Surface cell)

F: (Fluid cell), 0: (Object cell)

Fig. 2. Drift treatment.

following $k-\varepsilon$ model of turbulent flow to calculate Reynolds stress $-\overline{u_{i}^{\prime} u_{j}^{\prime}}$.

$$
\begin{aligned}
& -\overline{u_{i}^{\prime} u_{j}^{\prime}}=\frac{C_{\mu} k^{2}}{\varepsilon}\left(\frac{\partial \bar{u}_{i}}{\partial x_{j}}+\frac{\partial \bar{u}_{j}}{\partial x_{i}}\right)-\frac{2}{3} k \delta_{i j} \\
& \frac{\partial k}{\partial t}+\frac{1}{\gamma^{\mathrm{v}}} \frac{\partial \gamma_{j}^{\mathrm{a}} k \bar{u}_{j}}{\partial x_{j}}=\frac{\partial}{\partial x_{j}}\left[\left(v+\frac{C_{\mu} k^{2}}{\sigma_{k} \varepsilon}\right) \frac{\partial k}{\partial x_{j}}\right] \\
& -\overline{u_{i}^{\prime} u_{j}^{\prime}} \frac{\partial \bar{u}_{i}}{\partial x_{j}}-\varepsilon \\
& \frac{\partial \varepsilon}{\partial t}+\frac{1}{\gamma^{\mathrm{v}}} \frac{\partial \gamma_{j}^{\mathrm{a}} \varepsilon \bar{u}_{j}}{\partial x_{j}}=\frac{\partial}{\partial x_{j}}\left[\left(v+\frac{C_{\mu} k^{2}}{\sigma_{\varepsilon} \varepsilon}\right) \frac{\partial \varepsilon}{\partial x_{j}}\right] \\
& -C_{\varepsilon 1} \frac{\varepsilon}{k} \overline{u_{i}^{\prime} u_{j}^{\prime}} \frac{\partial \bar{u}_{i}}{\partial x_{j}}-C_{\varepsilon 2} \frac{\varepsilon^{2}}{k}
\end{aligned}
$$

where $k\left(\equiv \overline{u_{i}^{\prime} u_{i}^{\prime}} / 2\right)$ is the turbulent energy, $\varepsilon\left(\equiv v \overline{u_{i, j}^{\prime} u_{i, j}^{\prime}}\right)$ is the turbulent energy dissipation, and $\delta_{i j}$ is the Kronecker delta. The constant numbers in Eqs. (4), (5), and (6) are $\sigma_{k}=1.0, \sigma_{\varepsilon}=1.3, C_{\varepsilon 1}=1.45, C_{\varepsilon 2}=1.92, C_{\mu}=0.09$.

Our method is based on the SIMPLE method (Patankar and Spalding, 1972); we use discretized equations (Eqs. (1), (2), and (3)) on the Cartesian coordinate system to represent

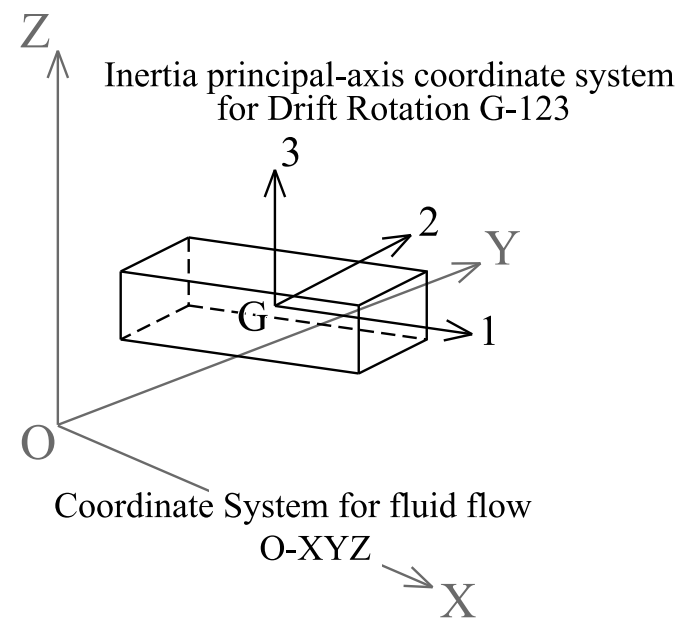

Fig. 3. Coordinate system for fluid flow and drift rotation.

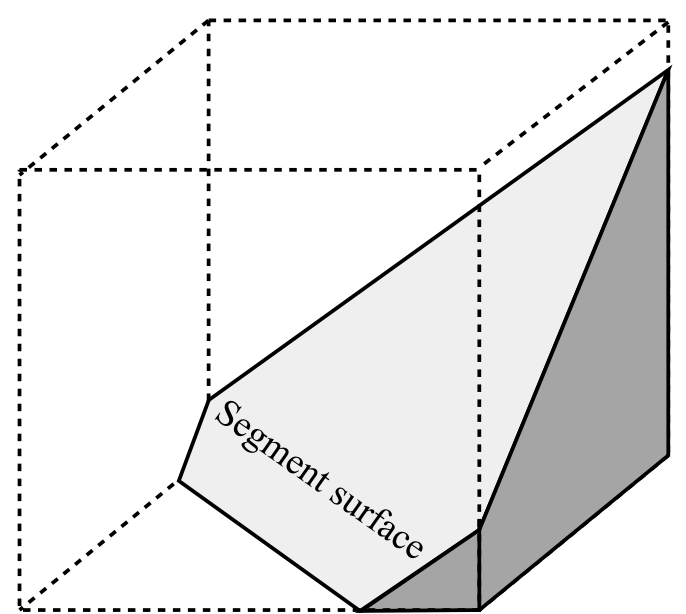

Fig. 4. Segment and segment surface in a cell.

fluid flow. The definition points of the flow velocity and the others were at the center of the boundary phase between the cells and at the centers of the cells, respectively. The discretizations of time, advective term, and others yielded the forward difference, third-order upwind difference, and centered difference, respectively. Moreover, we discretized Eq. (3) using the volume of fluid (VOF) method (Hirt et al., 1981). We also devised a few countermeasures to conserve fluid volume (Yoneyama, 1998).

\subsection{Basic equations of driftage motion}

The driftage motion calculation is based on rigid motion analysis. In addition to the Cartesian coordinate system used in fluid analysis, an inertia principal-axis coordinate system is used for the analysis of driftage motion. The coordinate system moves with a driftage, and its origin is the centroid (gravity center) of the driftage (see Fig. 3).

In this paper, the driftage contained in each calculation cell is called a "segment," and the surface of the driftage contained in each cell is called the "segment surface" (see Fig. 4). The basic equations of rigid motion are as follows. 


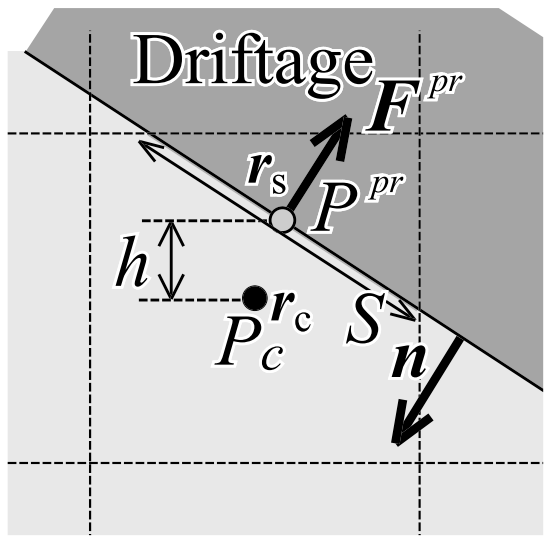

(a) In case of internal cell

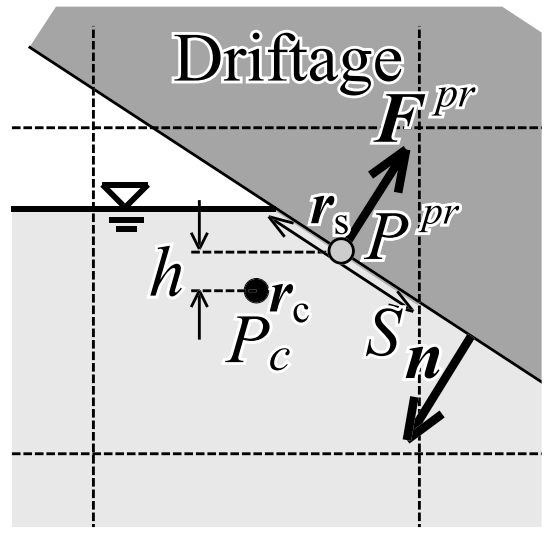

(b) In case of surface cell

Fig. 5. Pressure calculation.

- Equation of motion of the driftage centroid

$$
m \frac{d \boldsymbol{v}_{g}}{d t}=m \boldsymbol{g}+\sum_{k} \boldsymbol{F}_{k}^{\mathrm{pr}}+\sum_{k} \boldsymbol{F}_{k}^{\mathrm{vis}}
$$

- Equation of rotational motion about the driftage centroid

$$
\mathcal{I} \frac{d \boldsymbol{\omega}}{d t}+\boldsymbol{\omega} \times \mathcal{I} \boldsymbol{\omega}=\sum_{k}\left\{\widetilde{\boldsymbol{r}}_{\boldsymbol{S}_{k}} \times\left(\boldsymbol{F}_{k}^{\mathrm{pr}}+\boldsymbol{F}_{k}^{\mathrm{vis}}\right)\right\}
$$

where $m$ is the mass of the driftage, $\boldsymbol{v}_{g}$ is the driftage centroid velocity vector, and $\boldsymbol{F}_{k}^{\mathrm{pr}}$ and $\boldsymbol{F}_{k}^{\mathrm{vis}}$ are the vectors of the fluid pressure and viscous force, respectively, acting on the segment surface. $\boldsymbol{\omega}$ is an angular velocity vector on the inertia principal-axis coordinate system. $\mathcal{I}$ is an inertia tensor that consists of the inertia moment of driftage. $\widetilde{\boldsymbol{r}}_{\boldsymbol{S}_{k}}$ is the position vector of the centroid of a segment surface on the inertia principal-axis coordinate system.

\subsection{Algorithm of fluid force that acts on driftage}

2.3.1 Pressure $\boldsymbol{F}^{\mathbf{p r}}$ As shown in Eq. (9), the pressure that acts on a "segment surface" $P$ pr is estimated by using the cell pressure $P_{\mathrm{c}}$ (see Fig. 5).

$$
P^{\mathrm{pr}}=P_{\mathrm{c}}-\rho g h=P_{\mathrm{c}}-\rho g\left(\boldsymbol{r}_{\mathrm{s}}-\boldsymbol{r}_{\mathrm{c}}\right)_{z}
$$

where $h$ is the vertical interval between the centroid of a segment surface and the cell center; $\boldsymbol{r}_{\mathrm{s}}$, the position vector of the centroid of a segment; and $\boldsymbol{r}_{\mathrm{c}}$, the position vector of the cell center. In this estimation, a hydrostatic pressure is assumed to be acting between the centroid of a segment surface and the cell center. Therefore, the fluid pressure acting on a segment surface is expressed by

$$
\boldsymbol{F}^{\mathrm{pr}}=P^{\mathrm{pr}} S(-\boldsymbol{n}) .
$$

where $S$ is the area of a segment surface and $\boldsymbol{n}$, the normal vector of the surface. In case of a cell including a water surface, a centroid and an area of the submerged part of the segment surface are used for estimation (see Fig. 5(b)).

2.3.2 Viscous force $\boldsymbol{F}^{\mathrm{vis}}$ If $\boldsymbol{U}(\boldsymbol{r})$ is a velocity vector at a position $\boldsymbol{r}$, then the component of the velocity vector parallel to a segment surface $\boldsymbol{U}_{\mathrm{p}}$ is expressed as follows.

$$
\boldsymbol{U}_{\mathrm{p}}=\boldsymbol{U}-(\boldsymbol{n} \cdot \boldsymbol{U}) \boldsymbol{n}
$$

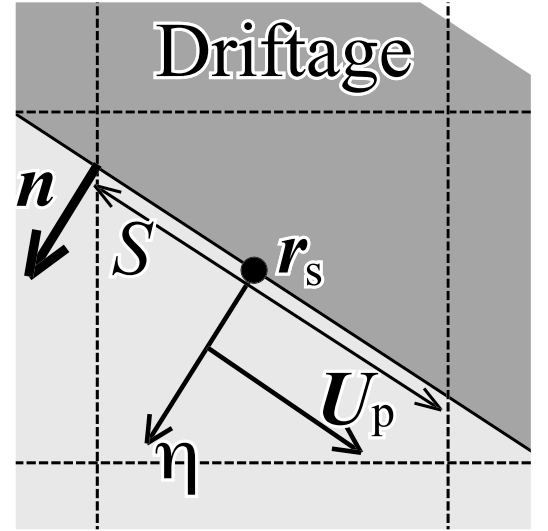

Fig. 6. Viscosity calculation.

If $\boldsymbol{r}_{\mathrm{s}}$ is the centroid of a segment surface, then the shear stress on the surface, $\boldsymbol{\tau}\left(\boldsymbol{r}_{\mathrm{s}}\right)$ is expressed as follows (see Fig. 6).

$$
\boldsymbol{\tau}\left(\boldsymbol{r}_{\mathrm{s}}\right)=\left.\mu \frac{\partial \boldsymbol{U}_{\mathrm{p}}}{\partial \eta}\right|_{\boldsymbol{r}=\boldsymbol{r}_{\mathrm{s}}}
$$

where $\mu$ is the viscosity coefficient of the fluid and $\eta$, a coordinate axis with origin $\boldsymbol{r}_{\mathrm{s}}$ that is directed along a normal vector $\boldsymbol{n}$.

Thus, the viscosity force acting on a segment surface $\boldsymbol{F}^{\mathrm{vis}}$ can be expressed as

$$
\boldsymbol{F}^{\mathrm{vis}}=\boldsymbol{\tau}\left(\boldsymbol{r}_{\mathrm{s}}\right) S=\left.\mu S \frac{\partial \boldsymbol{U}_{\mathrm{p}}}{\partial \eta}\right|_{\boldsymbol{r}=\boldsymbol{r}_{\mathrm{s}}} .
$$

\subsection{Calculation related to collision}

When the collision is predicted to occur before the following calculation step (between $t$ and $(t+\Delta t)$ ), the motion of the driftage is calculated as follows.

i) Calculate the velocity of the driftage centroid, $\boldsymbol{v}_{g}$, and the angular velocity of the inertia principal-axis, $\omega$, using the basic equations of driftage motion. 


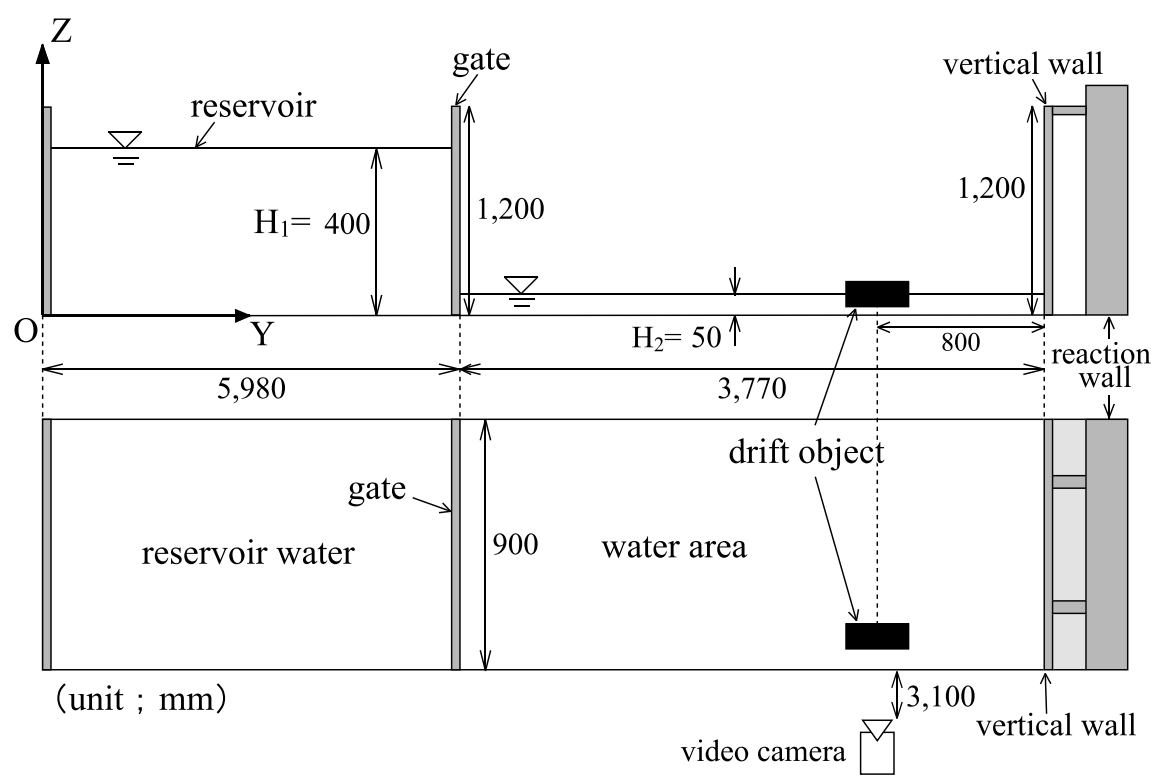

Fig. 7. Experimental apparatus used in Case 1.

ii) Calculate the time of the collision occurrence $(t+$ $\left.\Delta t_{\text {col }}\right)$ and the position vector of the collision point on the inertia principal-axis $\boldsymbol{r}_{\mathrm{col}}$ using $\boldsymbol{v}_{g}$ and $\boldsymbol{\omega}$.

iii) Calculate the velocity of the driftage centroid $\boldsymbol{v}_{g}{ }^{\prime}$ and the angular velocity of the inertia principal-axis $\omega^{\prime}$ immediately after collision using the following equations.

$$
\begin{aligned}
\boldsymbol{v}_{g}{ }^{\prime} & =\boldsymbol{v}_{g}+\frac{J}{m} \boldsymbol{n}_{\mathrm{col}} \\
\boldsymbol{\omega}^{\prime} & =\boldsymbol{\omega}+\mathcal{I}^{-1}\left(\boldsymbol{r}_{\mathrm{col}} \times J \boldsymbol{n}_{\mathrm{col}}\right)
\end{aligned}
$$

where $\boldsymbol{n}_{\mathrm{col}}$ is the normal vector of the collision surface (wall, bed etc); and $J$, the impulse force, given by the following expression.

$$
J=\frac{-(e+1)\left(\boldsymbol{v}_{g}{ }^{\prime}+\boldsymbol{\omega}^{\prime} \times \boldsymbol{r}_{\mathrm{col}}\right) \cdot \boldsymbol{n}_{\mathrm{col}}}{1 / m+\left\{\left[\mathcal{I}^{-1}\left(\boldsymbol{r}_{\mathrm{col}} \times \boldsymbol{n}_{\mathrm{col}}\right)\right] \times \boldsymbol{r}_{\mathrm{col}}\right\} \cdot \boldsymbol{n}_{\mathrm{col}}}
$$

where $e$ is the reflection coefficient.

iv) Calculate the position of driftage centroid $X_{g}$ and rotation angle of inertia principal-axis $\theta_{g}$ at time of $t+\Delta t$ by using $\boldsymbol{v}_{g}, \omega, \boldsymbol{v}_{g}{ }^{\prime}$ and $\omega^{\prime}$.

In this procedure, $\boldsymbol{F}^{\mathrm{pr}}$ and $\boldsymbol{F}^{\mathrm{vis}}$ is not changed before and after the collision. Equations (14) and (15) are derived from the Lagrangian equation of impulsive motion, which was applied the Newton's hypothesis.

\subsection{Calculation procedure}

The calculation procedure is as follows:

i) Read the input data.

ii) Set the boundary condition for flow velocity $u_{i}^{n}$ and pressure $p^{n}$ at time $t$.

iii) Calculate the turbulence energy $k^{n+1}$, the turbulent energy dissipation $\varepsilon^{n+1}$, and the eddy viscosity $v_{t}^{n+1}$ at time $t+\Delta t$.

iv) Calculate the flow velocity $u_{i}^{n+1}$ at time $t+\Delta t$ using the discretized form of Eq. (2). v) Calculate the position and rotation angles of the driftage, $X_{g_{i}}^{n+1}$ and $\theta_{g}^{n+1}$, respectively, at time $t+\Delta t$ using the discretized forms of Eqs. (8) and (9).

vi) Calculate the void ratio and aperture ratio, $\gamma^{\mathrm{v} n+1}$ and $\gamma_{i}^{\mathrm{a} n+1}$, respectively, at time $t+\Delta t$.

vii) Calculate the error in the continuity equation $D$ using the discretized form of Eq. (1). If $D$ exceeds the limit $D_{\max }$, then correct the pressure $p^{n+1}$ on the basis of the solution of the pressure error equation and return to step iv). If not, then proceed to step viii).

viii) Calculate the fluid-filling ratio $F^{n+1}$ at time $t+\Delta t$.

ix) If it is time to stop, then stop the calculation. If not, increase the time and return to step ii).

\section{Application and Discussion}

\subsection{Case 1: driftage in sea}

Ikeno et al. (2001) conducted a hydraulic experiment to determine the collision force of an object with a simple geometry drifted by a tsunami; they proposed a formula to determine the approximate collision force. Their experimental apparatus is shown in Fig. 7. The model scale is $1 / 100$. The gate was quickly opened, water from the reservoir flowed toward the wall, and the object drifted. The driftage in this case is a wooden object and its specific gravity is 0.5 . One side of the experimental flume is made of clear glass and the motion of the driftage was recorded from the glass side using a high-resolution video camera.

The experimental conditions for calculations using our method were as follows: Water levels were $H_{1}=40 \mathrm{~cm}$, $H_{2}=5 \mathrm{~cm}$. The driftage was a cylinder with a diameter of $8 \mathrm{~cm}$ and a height of $20 \mathrm{~cm}$. The initial position of the centroid of this object was $Y=8.95 \mathrm{~m}$. The computation conditions are as follows: The grid spacing is $6.5 \mathrm{~cm}$ along the direction across the flow, $6 \mathrm{~cm}$ along the flow direction, and $3 \mathrm{~cm}$ in the vertical direction. The computational time interval $\Delta t$ is $1.0 \times 10^{-3} \mathrm{~s}$, The maximum permissible error of the continuity equation $D_{\max }$ is $1.0 \times 10^{-5}$, 


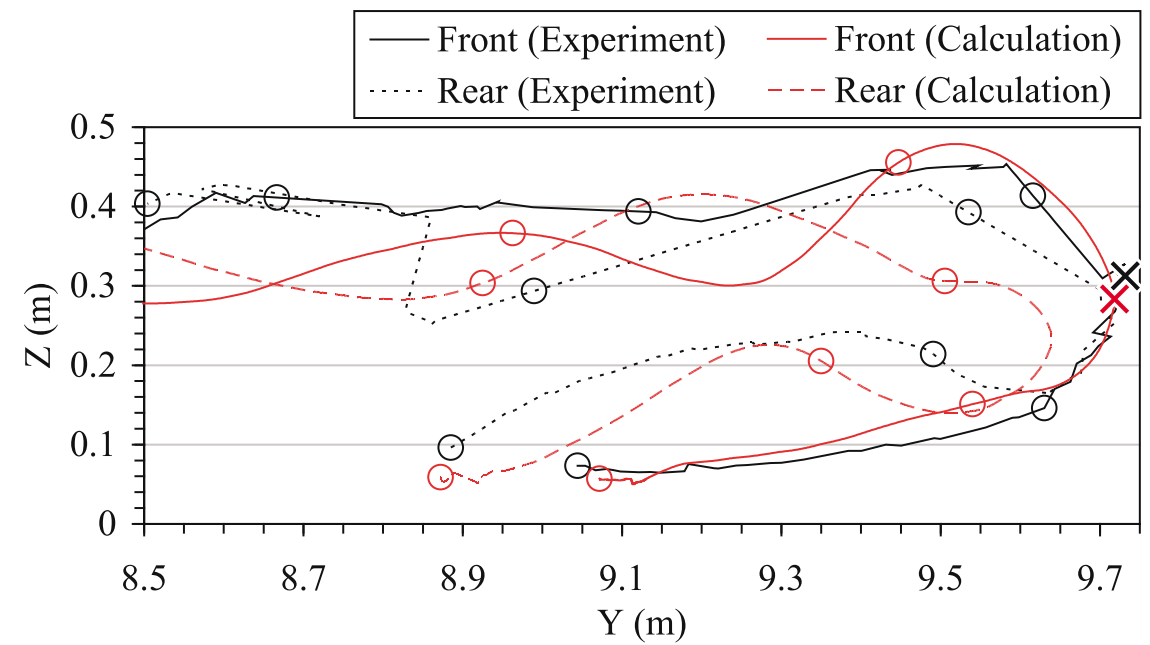

Fig. 8. Comparison of the trajectory patterns of the driftage obtained in Case 1.

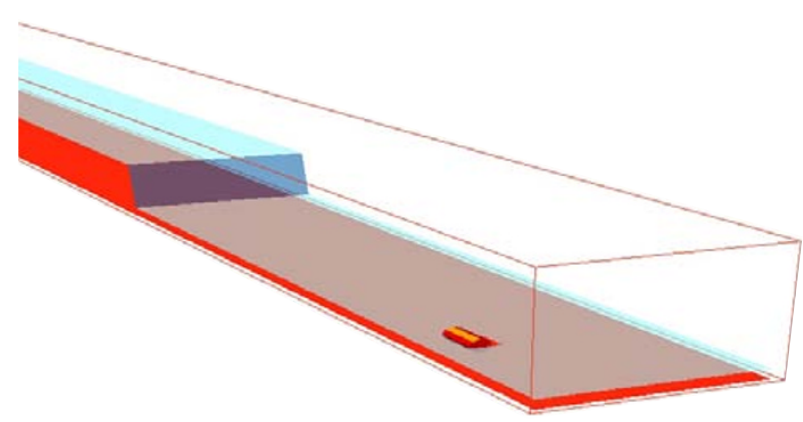

(a) $t=0.00 \mathrm{~s}$

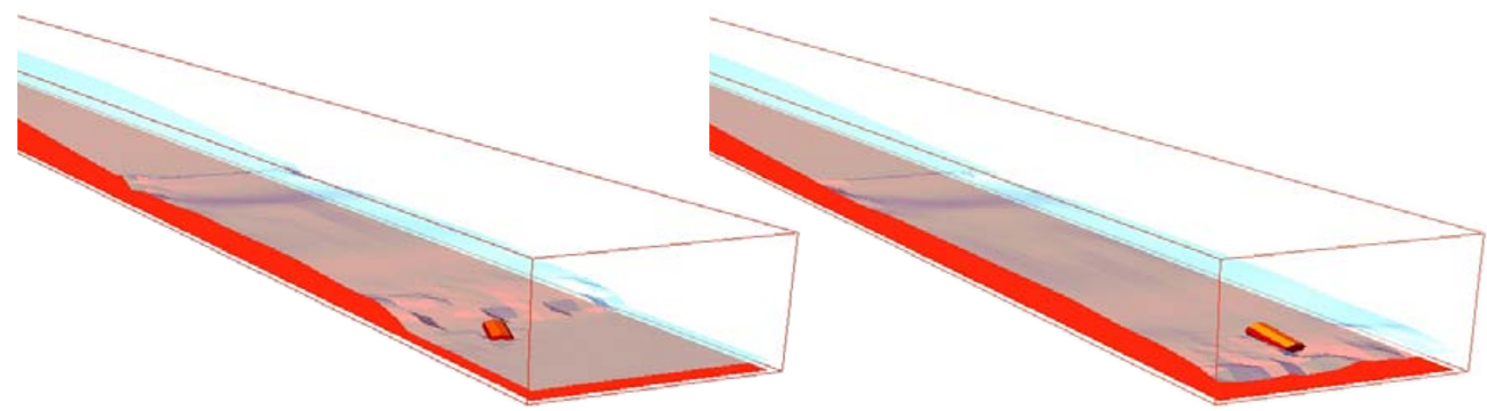

(b) $t=1.51 \mathrm{~s}$

(c) $t=2.01 \mathrm{~s}$

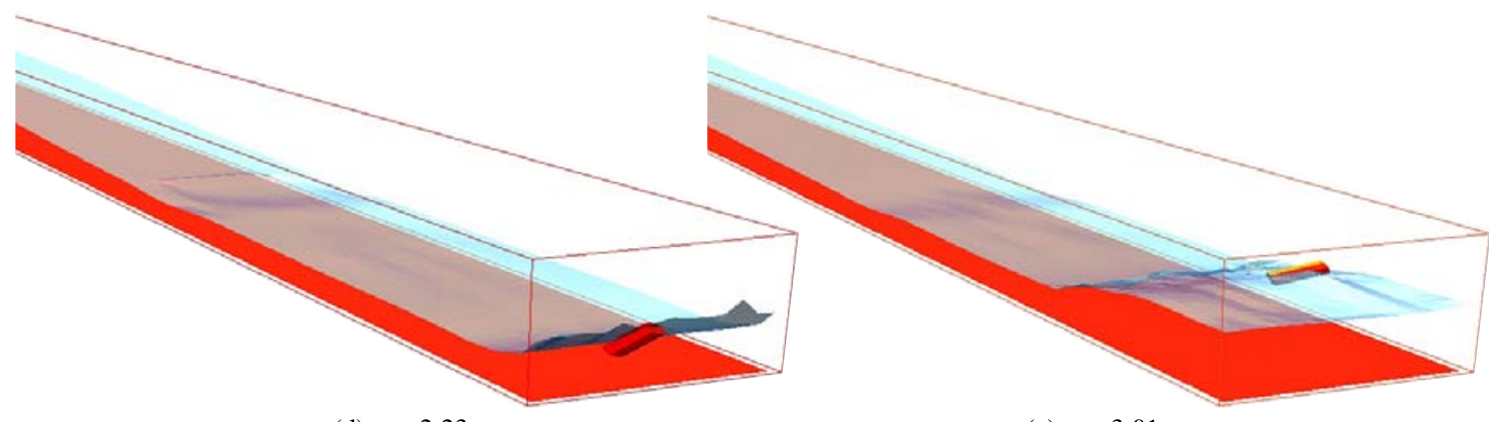

(d) $t=2.23 \mathrm{~s}$

(e) $t=3.01 \mathrm{~s}$

Fig. 9. Examples of computation results in Case 1. 


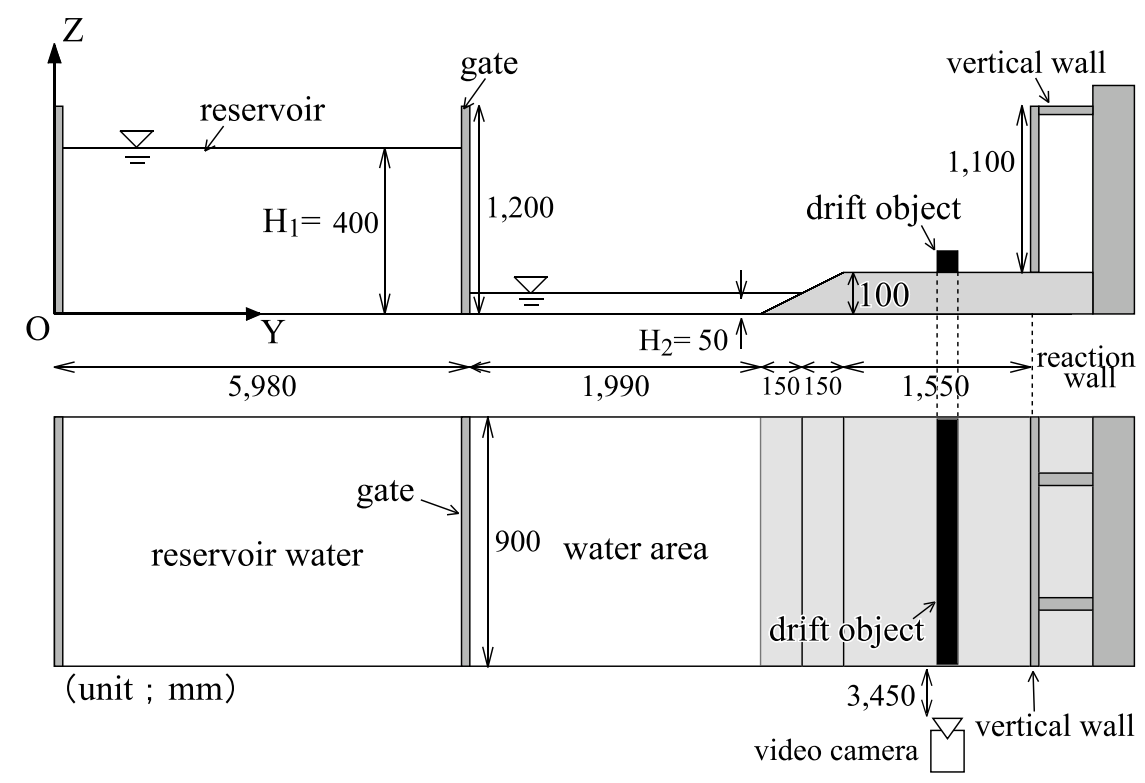

Fig. 10. Experimental apparatus used in Case 2.

fluid density $\rho$ is $1.0 \times 10^{3} \mathrm{~kg} / \mathrm{m}^{3}$, kinematic viscosity $v$ is $1.0 \times 10^{-6} \mathrm{~m}^{2} / \mathrm{s}$, density of the driftage $\rho_{d}$ is $0.5 \times 10^{3}$ $\mathrm{kg} / \mathrm{m}^{3}$, and the reflection coefficient between the driftage and vertical wall $e$ is 0.5 . For computational purposes, the cylindrical driftage was modeled as an octagonal pillar with cross-sectional area and volume equal to that of the actual cylinder (driftage).

Figure 8 shows the results of a comparison between the vertical 2D trajectory of the driftage obtained by the computation and that obtained in the experiment. In this figure, the trajectories of the centroid of the front-end face (land side) and the rear-end face (sea side) of the driftage are compared. The circles denote the location of the centroid of the frontand rear-end face of the driftage after every $0.5 \mathrm{~s}$ from the start of its motion. " $x$ " indicates the location where the driftage collided with the vertical wall.

Figure 9 shows examples of the simulation results. The time shown in this figure indicates the time elapsed since the start of the experiment.

As shown in Fig. 8, the computed driftage trajectory, time variation of the position, and point of collision are in good agreement with the corresponding experimental results. Therefore, we concluded that our code can successfully predict the behavior of driftage in the sea.

\subsection{Case 2: driftage on land}

Ikeno and Tanaka (2003) conducted another hydraulic experiment to determine the behavior of driftage on land. The experimental apparatus is shown in Fig. 10. This apparatus is the same as that in Case 1 with the exception of a 10-cm-high ground segment in the front of the vertical wall. The driftage is a square pillar with side $4.5 \mathrm{~cm}$ and height $89 \mathrm{~cm}$. The initial position of the driftage centroid is $Y=9.02 \mathrm{~m}$. The other experimental and computational conditions are the same as those in Case 1. In the analysis, the bottom surface of the driftage is raised by $0.005 \mathrm{~m}$ from the surface of the ground segment. This was done so that the water flowing through the $0.005-\mathrm{m}$ gap would exert an upward force on the driftage.

Figure 11 shows the results of a comparison between the vertical $2 \mathrm{D}$ trajectory of the driftage obtained by the computation and that obtained in the experiment. In this figure, the trajectories of the driftage centroid are compared. The circles and the " $x$ " carry the same meaning as in Fig. 8.

Figure 12 shows examples of the simulation results.

As shown in Fig. 11, the computed trajectory elevation of the driftage between the initial position and the vertical wall was higher than the experimental result. Therefore, the collisions that occurred at low elevations in the experiment did not show in the computation results. This difference might be caused by the initial gap between the driftage and the ground surface. In future works, it is necessary to understand the mechanism of initial movement and to find a suitable initial condition.

However, in general, the computed drifting behavior agrees well with the experimental results despite the initial movement problem. Therefore, we concluded that our code can successfully predict the behavior of driftage on land.

\section{Conclusion}

The results of our research are summarized as follows:

- A numerical analysis code has been developed to predict the behavior of driftage carried by a tsunami. The main features of the code are as follows.

- It can simulate driftage motion with six degreesof-freedom in a 3D flow field.

- It can consider the interaction between a fluid flow and a driftage motion.

- It can determine the impact of the collision of driftage with a wall on the basis of the Lagrangian equation of impulsive motion.

- To verify the validity of the code, the obtained computational results were compared with the results of two 


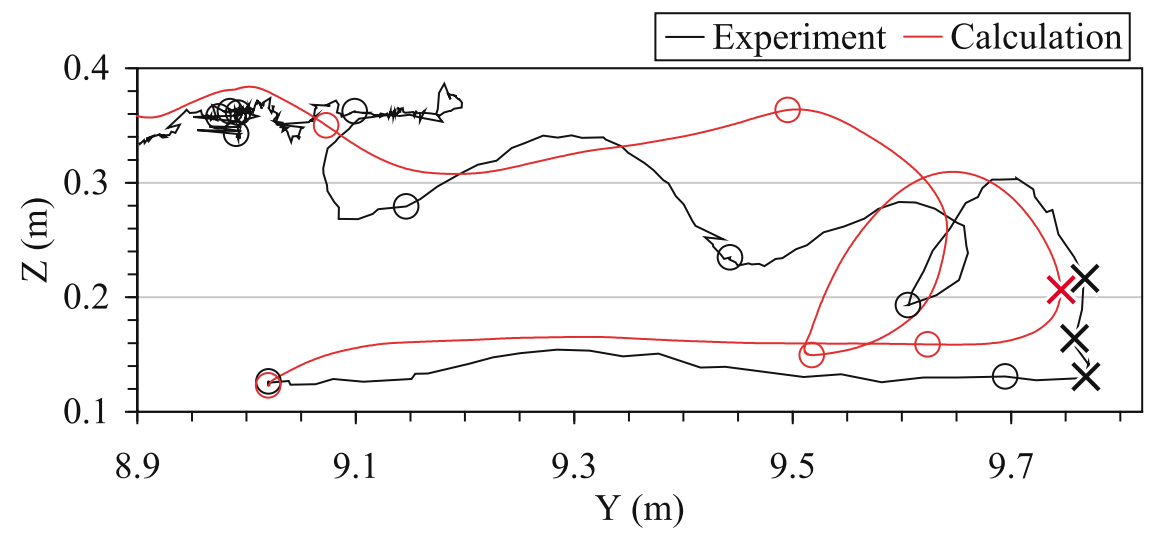

Fig. 11. Comparison of the trajectory patterns of the driftage obtained in Case 2.

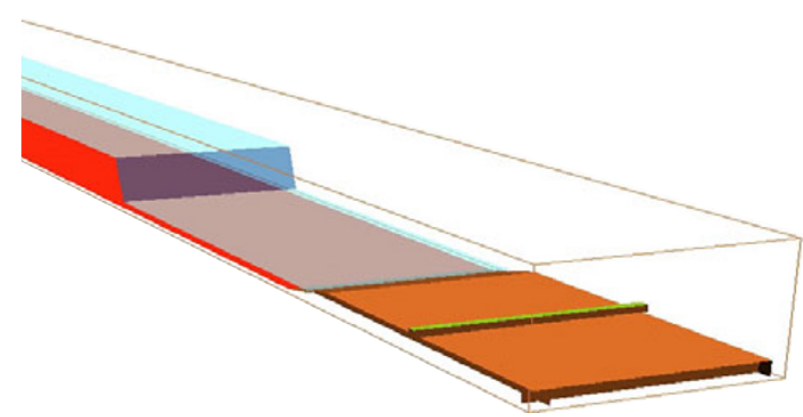

(a) $t=0.00 \mathrm{~s}$

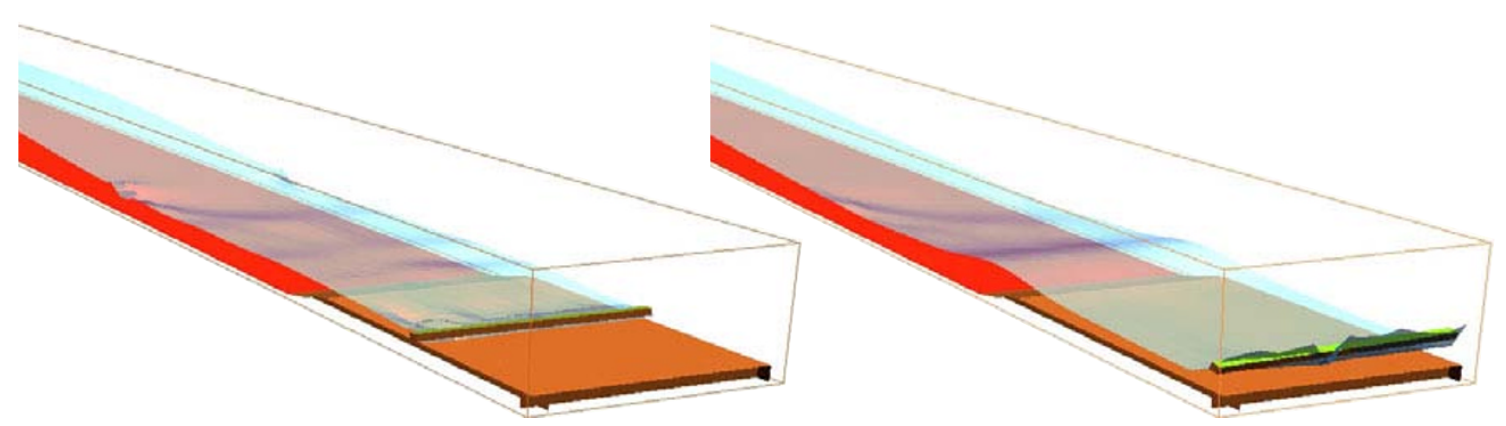

(b) $t=1.51 \mathrm{~s}$

(c) $t=2.04 \mathrm{~s}$

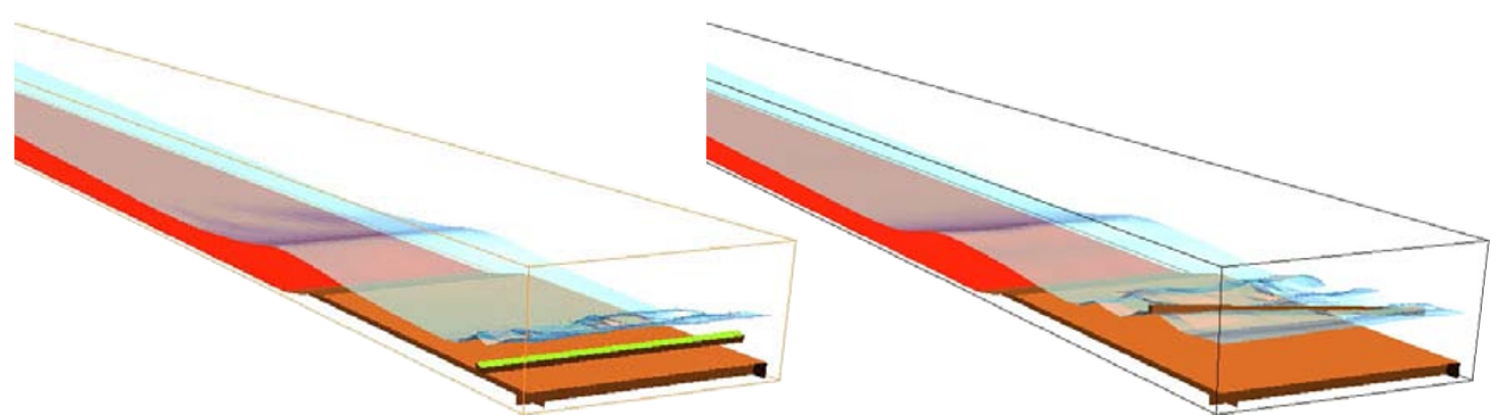

(d) $t=2.50 \mathrm{~s}$

(e) $t=3.01 \mathrm{~s}$

Fig. 12. Examples of computation results obtained in Case 2. 
hydraulic experiments. The behavior of driftage and the time variation of its position as calculated using our code were in good agreement with the experimental results.

- It can be concluded that our code can be used to successfully predict the behavior of driftage carried by a tsunami.

In the future, the code will be applied to various drifting motions and it will be improved such that it can be used to simultaneously predict the behavior of several drifting objects. Furthermore, a method will be developed to determine the collision force; this was not discussed in this paper.

Acknowledgments. The authors are indebted to Dr. Masaaki Ikeno, Central Research Institute of Electric Power Industry, Japan, for kindly supplying his experiment data.

\section{References}

Hirt, C. W. and B. D. Nichols, Volume of fluid (VOF) method for the dynamics of free boundaries, J. Comput. Phys., 39, 201-225, 1981.
Ikeno, M. and H. Tanaka, Experimental study on impulse force of drift body and tsunami running up to land, Ann. J. Coast. Eng., JSCE, 50, 721-725, 2003.

Ikeno, M., N. Mori, and H. Tanaka, Experimental study on drift behavior and its impulse force by tsunami, Ann. J. Coast. Eng., JSCE, 48, 846850, 2001.

Kawasaki, K., S. Yamaguchi, M. Hakamada, N. Mizutani, and S. Miyajima, Wave pressure acting on drifting body after collision with bore, Ann. J. Coast. Eng., JSCE, 53, 786-790, 2006.

Nagashima, H., N. Yoneyama, and K. Toda, Numerical analysys of the drift behavior in tsunami run-up using the FAVOR method, Adv. Hydro-Sci. Eng., VIII, CD-ROM, 2008.

Patankar, S. V. and D. B. Spalding, A calculation procedure for heat, mass and momentum transfer in three-dimensional parabolic flow, J. Heat Mass Transfer, 15, 1787, 1972.

Ushijima, S., S. Yamada, S. Fujioka, and I. Nezu, Prediction method (3D MICS) for transportation of solid bodies in 3D free-surface flows, $J$. Hydrau. Coast. Environ. Eng., JSCE, 810/II-74, 79-89, 2006.

Yoneyama, N., Development of free surface hydraulic analysis code (FRESH), Nagare (Jpn. Soc. Fluid Mech.), 17(3), 1998.

Yoneyama, N., M. Matsuyama, and H. Tanaka, Numerical analysis for locally high runup of 1993 Hokkaido Nansei-oki Seismic Tsunami, $J$. Hydrau. Coast. Environ. Eng., JSCE, 705/II-59, 139-150, 2002.

N. Yoneyama (e-mail: yoneyama.nozomu.4w@kyoto-u.ac.jp), H. Nagashima, and K. Toda 